\title{
DIAMONDS STRUCTURAL CHARACTERISTICS FROM DIFFERENT PETROCHEMICAL TYPES OF KIMBERLITES
}

\author{
Kriulina GY $\mathbf{1}^{\mathbf{1}}$, Vasiliev EA ${ }^{\mathbf{2}}$, Garanin* $\mathbf{V K}^{\mathbf{1}}$, Garanin $\mathbf{K V}^{\mathbf{1}}$ \\ ${ }^{1}$ M.V. Lomonosov Moscow State University, Moscow, Russia; \\ ${ }^{2}$ G.V. Plekhanov Saint-Petersburg GGI (Technical University), Saint-Petersburg, Russia
}

\section{INTRODUCTION}

Within the Arkhangelsk and Yakutian diamondiferous provinces (Russia) wide range of kimberlitic rocks are known. These rocks are differing by petrographic and mineralogical features, but all the major typomorphic kimberlitic features are presented. Modern researches (Garanin et al., 2009, Bogatikov et al., 2010; Kononova et al., 2011, etc.) in the allocation of kimberlite varieties (groups) prefer $\mathrm{TiO}_{2}$ as the main selection criterion. A general classification of different petrogeoghemical kimberlite types was suggested (Bogatikov et al., 2010). It is based on the kimberlites division into three petrogeochemical types, conventionally called: low-titanium type (LTT) with $\mathrm{TiO}_{2}<1.0$ wt.\%, moderate-titanium type (MTT) with 1.0 $<\mathrm{TiO}_{2}<2.5$ wt.\%, and high-titanium type (HTT) with $\mathrm{TiO}_{2}>2.5$ wt.\%.

Diamonds from LTT and MTT kimberlites of the Arkhangelsk (ADP) and Yakutian (YDP) diamondiferous provinces were selected for the present investigation. These kimberlite types compose diamondiferous pipes, which are economically effective for mining (e.g. industrial primary diamond deposits), the while HTT kimberlites represent only low- or nondiamondiferous bodies.

Diamonds from LTT kimberlites were presented by crystals from Snegurochka, Karpinskogo-1, Archangelskaya (Zolotitskoe field, ADP), Internatsionalnaya (Mirninskoe field, YDP), Botuobinskaya (Nakynskoe field, YDP) pipes. Diamonds from MTT kimberlites presented by crystals from V. Grib (Chernoozerskoe field, ADP), Mir (Mirninskoe field, YDP), Udachnaya (Daldynskoe field, YDP), Komsomolskaya, Yubileinaya (Alakit-Markhinskoe field, YDP).

\section{RESULTS}

The realized study allows to identify the distinguish characteristics of diamonds from LTT and MTT kimberites.

The greatest range of colors and frequency of colored diamonds occurrence among octahedron-dodecahedron habit row describe the diamonds from the LTT kimberlites. Crystals with yellow, gray, smoky-brown color are dominated. It is important to emphasize that diamonds with fancy intense colors (pink-purple, blue, orange (red-brown) are also presented. The share of colorless stones is minimal (less than 10\%), diamonds with a slight tinge are extended 20-25\%, and yellow crystals with shade of varying intensity are dominated (30-54\%).

Among the octahedrons-dodecahedrons from MTT kimberlites the colorless and diamonds with a slight tinge are dominated by (33-60\%) with a significant proportion of epigenetically smokybrown colored crystals (14\% in the V. Grib pipe and up to $45 \%$ in the Udachnaya pipe). The share of the yellow-colored crystals with a visible tint 


\section{$10^{\text {th }}$ International Kimberlite Conference, Bangalore - 2012}

is negligible (9-19\%), compared with diamonds from LTT kimberlites.

The ratio of plane, plane-curve-faced and curve-faced diamonds is individually for each deposit. A tendency of increasing the proportion of plane-curve-faced and curve-faced crystals with a decreasing of diamond grade is registered. The diamonds from MTT kimberlites are characterized by a predominance of plane and plane-curve-faced crystals shapes. The diamonds from LTT of the ADP are characterized by a predominance curvefaced and combinational shapes, while among the diamonds from LTT of the YDP presented mostly by plane (Internatsionalnaya pipe), plane-shape and combinational diamonds (Botuobinskaya and Nurbinskaya pipes). It is important to emphasize that with increasing the size of diamonds of the M.V. Lomonosov deposit pipes the share of curvefaced and combinational diamonds is also increasing, but among the studied deposits of YDP (both for MTT and LTT kimberlites) the bucking trend is observed: increasing plane-octahedral crystals quantity with increasing large size- weight diamonds groups.

Diamonds from LTT kimberlites are characterized by a predominance of plane-faced and plane-curve-faced crystals with a polycentric faces character, and (rarely) the skeletal octahedral crystals formation. It indicates the crystallization environment oversaturation by hydrocarbons (Zinchuk, Koptil, 2003) and gives evidence that these diamonds were generated in the thermodynamic conditions of eclogite paragenesis. Among octahedral and dodecahedral habit diamonds from ADP common crystals with a fiber and combinational (normal+tangential) growth mechanism, with a common zoning and interleaving growth mechanisms, which is due to growth in an unstable, fluctuating changing conditions. The presence of diamonds with fibrous coat and cubic habit crystals with the normal and combinational growth mechanism suggests: a discrete diamond formation in the pipes, high thermal gradient conducive to the defect structure formation and the large amounts seizure of impurities by cubic growth sectors, and rapid forms' transformation in the dodecahedral ones during the post-growth oxidation.

Diamonds from MTT kimberlites grew up in the stable high-temperature conditions that contributed to the formation of crystals with a homogeneous internal structure with a fiber growth mechanism (layer-oxidation is slower than for the fibrous structures). The presence of moderate titanium concentrations in the environment is very important. Titanium has a very important properties, has a positive impact on the diamond quality: it binds nitrogen and prevents its entry into the diamond structure, and it is an inhibitor of the diamond oxidation. These parameters have contributed to the diamond preservation, although a longer postcrystallization annealing at elevated temperatures, whereby the crystals from the Udachnaya, Yubileinaya and Komsomolskaya pipes are distinguished by higher strength properties.

13 Defect-impurity composition of the

diamond. High-nitrogen diamonds $\left(50<\mathrm{N}_{\text {tot }}<3000\right.$ at.ppm) presence is typical for LTT kimberlites, which suggests significant nitrogen concentrations in the diamond-forming environment. Diamonds with the defect-impurity centers in the A-form are prevailing for all pipes except Internatsionalnaya, a bimodal distribution is typically.

Elevated concentrations of nitrogen and hydrogen defect-impurity centers negative impact on diamond quality: the diamond with high nitrogen content in the structure has an increased fragility. Nitrogen content in the B-form is reduced (mean $\mathrm{N}_{\mathrm{B}} \rightarrow 30 \%$ ), marked by low rates of Platelets absorption $\left(2<\mathrm{R}_{\text {average }}<5 \mathrm{~cm}^{-1}\right.$, with the exception for diamonds from the Snegurochka pipe where $\mathrm{R}_{\text {average }}=8.5 \mathrm{~cm}^{-1}$ ), with the shift of position absorption band of the IR-spectrum to shorter wavelengths, which according to published data (Taylor, Milledge, 1995; Bogush et al., 2009), indicates a short duration of the post- 


\section{$10^{\text {th }}$ International Kimberlite Conference, Bangalore - 2012}

crystallization annealing in the magmatic substrate at temperatures required for the transformation of nitrogen defects (more than $900^{\circ} \mathrm{C}$ ), while the low absorption coefficients of the $1364-1370 \mathrm{~cm}^{-1}$ band indicate relatively low temperatures during the formation of diamond crystals. Diamonds typomorphic feature for studied LTT kimberlites of YDP is the octahedral crystals predominance, whereas for LTT kimberlites of ADP curve-faced diamonds are prevail, consequently, the diamond oxidation occurred at relatively low temperatures (when the nitrogen aggregation from A- to B-form was not possible). It is well correlated with mineralogical and petrochemical characteristics of microcrystalline oxide minerals in kimberlite groundmass. At the same time a gradual increase in oxygen fugacity, the presence of catalysts, presumably contributed to the oxidation, as well as the defect structure itself, as the most intense etching occurs on the surface formed by the normal growth mechanism.

The deposits formed by MTT kimberlites are characterized by the low-nitrogen diamond crystals $\left(\mathrm{N}_{\text {tot }}<500\right.$ at.ppm.). The diamonds have undergone a longer post-crystallization annealing, and therefore most individuals have a greater proportion of nitrogen in aggregated B-form $\left(50<\mathrm{N}_{\mathrm{B}}<95 \%\right)$. A higher content of Platelets (5$10 \mathrm{~cm}^{-1}$ ) and the location of its peak in the IRspectrum at $1364 \mathrm{~cm}^{-1}$ indicate the diamond formation at elevated temperatures with longer high-temperature annealing, as compared with crystals from LTT kimberlites.

Diamonds from the ADP and YDP pipes differ in the hydrogen content. Totally for diamonds from M.V. Lomonosov deposit are characterized by higher hydrogen defects concentrations compare to diamonds from LTT kimberlites of YDP. Studies have shown (Blinova, 1987; Beskrovanov, 2000) that the hydrogen impurity content in the crystals are linked to their growth mechanism: crystals, formed as a result of the tangential growth mechanism, which manifests itself in layers-closed octahedral structure, the hydrogen centers are presented in low quantities, it is most typical for diamond deposits in Yakutia; diamonds with normal and combinational growth mechanism, common in the M.V. Lomonosov deposit, are characterized by fibrous and sectorial internal structure, and distinguished by maximal highest hydrogen concentrations.

Higher proportion of diamonds with mineral and fluid inclusions was identified for LTT kimberlites. Note that bands with low absorption coefficients (it is corresponding to the carbonates impurities or micro-inclusions, very rarely - hydroxyl groups and water) sometimes recorded in the IR-spectrum.

MTT Kimberlites are characterized by the presence of diamond with the lowest inclusions quantity and distinguished by higher water concentrations as inclusions in deep-seated accessory minerals (diamond, garnet, clinopyroxene, etc.).

On the one hand the presence aqueous fluids in diamond crystallization system are confirmed by research results of own diamonds, in which among the others inclusions water fluids were discovered: water availability is fixed by the wide IR-spectrum peak at $3440 \mathrm{~cm}^{-1}$. On the other hand significant diamonds number has anti-skeleton growth character. According to experimental studies it was found that formation of these crystals occurred in an environment saturated with water vapor. Crystals with combinational pseudododecahedron surfaces are much more common in the Mir, Komsomolskaya and Udachnaya pipes than in the Botuobinskaya and Archangelskaya pipes. It is established that the safety of the diamond shapes in the pipes which composed by MTT higher than for the crystals from LTT kimberlite pipes, despite long being in a hightemperature mantle metasomatism, reflected on the diamond crystals by nitrogen defects transformation $(\mathrm{A} \rightarrow \mathrm{B})$ and rounded shapes. 


\section{$10^{\text {th }}$ International Kimberlite Conference, Bangalore - 2012}

\section{DISCUSSION}

Seven diamond's groups were identified after studying and analyzing of structural defects in diamonds from industrial kimberlitic deposits of ADP and YDP (Fig. 1). Indicated groups in aggregate with kimberlites mineral composition features assume different in composition of diamond-generating substrate and kimberlitic magmas formation conditions.

The LTT kimberlites formed in mantle EMItype and characterized by presentation of relatively low quality of diamonds. There are higher quantity of diamonds with yellowish tint, with mineral and water-fluid inclusions, and also diamonds indicate higher concentrations of nitrogen defect-impurities $\left(50<\mathrm{N}_{\text {tot }}<3000\right.$ at.ppm) centers and hydrogen $\left(\mathrm{H}<10 \mathrm{~cm}^{-1} \mathrm{H}_{\text {average }}=2.5 \mathrm{~cm}^{-}\right.$ ${ }^{1}$ ) in such type of kimberlites. Octahedrondodecahedron row diamonds have low B-form nitrogen concentrations (at the average $\mathrm{NB} \leq 30 \%$ ), low coefficient Platelets absorption $\left(2<\mathrm{P}_{\text {average }}<5\right.$ $\mathrm{cm}^{-1}$, except for diamonds from Snegurochka pipe where $\mathrm{P}_{\text {average }}=8.5 \mathrm{~cm}^{-1}$ ) with a shifting of the IRspectrum band absorption maximum in long-wave region.

The MTT kimberlites formed in mantle EMII-type and characterized by presentation of higher quality diamonds compare to LTT kimberlites. There is lower quantity of diamonds with mineral inclusions, typical colorless or slight yellowish hue crystals with low nitrogen impurities concentration $\left(\mathrm{N}_{\text {tot }}<500\right.$ at.ppm) and low/absence hydrogen impurities $\left(\mathrm{H}<5, \mathrm{H}_{\text {average }}=1\right.$ $\left.\mathrm{cm}^{-1}\right)$. Obviously diamonds undergo prolonged post-crystallization anneal and in consequence crystals mostly have higher nitrogen B-form concentrations $\left(25<\mathrm{N}_{\mathrm{B}}<90 \%\right)$. Higher Platelets concentration $\left(5-10 \mathrm{~cm}^{-1}\right)$ and its maximum location in IR-spectrum $\left(\sim 1364 \mathrm{~cm}^{-1}\right)$ is an evidence that diamonds from MTT kimberlites were formed in higher temperature conditions compare to the diamonds from LTT kimberlites.

\section{CONCLUSION}

Investigation results suggest a conclusion that the diamond crystals of relatively low quality characteristics (strength and gemological) are dominated in LTT kimberlites, therefore there is a difficulty in processing them during cutting, because these diamonds have an imperfect structure. To the contrary diamonds with high gem and technological properties are typical for MTT kimberlites.

After realized comprehensive study of mineralogical and physical (spectroscopic) diamond properties, it is possible to suggest the selection of diamond groups for ADP and YDP deposits, which are typical: a) only for the LTT kimberlites; b) only for MTT kimberlites; c) for both LTT and MTT kimberlites (Fig. 1).

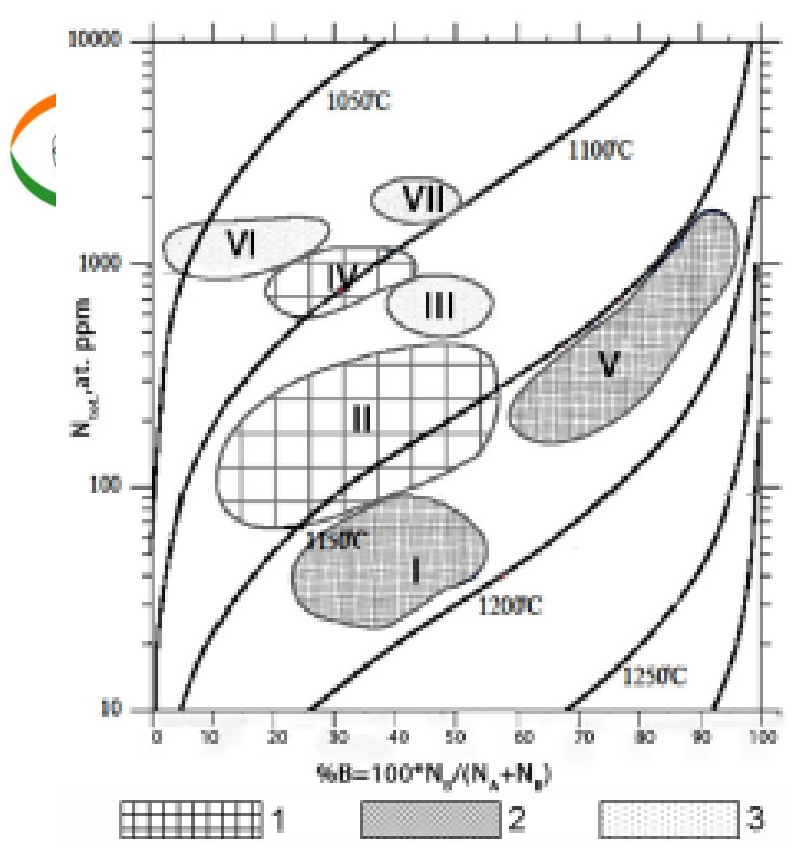

Fig. 1. Nitrogen concentrations for IàÀÂ type diamonds from ADP and YDP with using W.P. Taylor et al. data (1990). Estimated age of the diamond is 3 billion years. ADP and YDP diamonds groups are shown: I - nitrogen-free, II - low-nitrogen, III - moderate-nitrogen, IV - moderate-nitrogen and low-aggregated, $\mathrm{V}$ - moderate-nitrogen and high-aggregated, VI - high-nitrogen and low-aggregated, VII high-nitrogen and moderate-aggregated. Diamonds populations are indicated: 1 - typical for YDP and ADP, 2 - typical for YDP, 3 typical for ADP 


\section{$10^{\text {th }}$ International Kimberlite Conference, Bangalore - 2012}

\section{References}

Beskrovavnov V.V. Diamond ontogeny. Novosibirsk: Nauka. 2000. 264 p. In Russian

Blinova G.K. Structural impurities as indicators of nature diamond crystals growth mechanism // Dokl. AN SSSR CCCP, 1987. V. 294. ${ }^{1}$ 4. Pp. 868871. In Russian

Bogatikov O.A., Kononov V.A., Nosova A.A., Kargin A.V. Polygenic sources of kimberlites, magmas composition and diamond content (a comparative analysis of kimberlites from East-European and Siberian platforms) // Petrology. V. 3. ${ }^{1}$ 10. 2010. Pp. 5-26. In Russian

Bogush I.N., Pomazansky B.S, Kovalchuk O.E., Vasiliev E.A. The structural features of natural diamonds with different facet morphology of some Yakutian deposits // Simp.: Problems of forecasting and prospecting of diamond deposits in closed areas. Yakutsk. 2008. Pp. 151-157. In Russian

Garanin V.K., Bovkun A.V., Garanin K.V., Rothman A.Y., Serov I.V. Microcrystalline oxides from kimberlites and related rocks of Russia. Moscow: Publishing House of Moscow State University. 2009. 498 p. In Russian

Kononova V.A., Bogatikov O.A., Kondrashov I.A. Kimberlites and lamproites: criteria for similarities and differences. Petrology. V. 19. ${ }^{1}$ 1. 2011. Pp. 35-55. In Russian

Taylor W.R., Jaques A.L., Ridd M. Nitrogen-defect aggregation characteristics of some Australasian diamonds: time-temperature constraints on the source regions of pipe Pp. 1245-1260

Taylor W.R., Milledge H.J. Nitrogen aggregation character, thermal history and stable isotope composition of some xenolith-derived diamonds from Roberts Victor and Finch // Sixth Internal. Kimberlite Conf. Extended Abstr. Novosibirsk, August 1995. Pp. 620-622

Zinchuk N.N., Koptil V.I. Typomorphism of diamonds from the Siberian platform. Moscow. Nedra. 2003. 603 p. In Russian 